\title{
Mitigation of Uncertainties in Wind-Powered Renewable Systems for Environmental Assets
}

\author{
Subramani Pragaspathy ${ }^{1 *}$, Anand Baskaran ${ }^{2}$ \\ ${ }^{1}$ Nehru Institute of Engineering and Technology, Coimbatore, Tamilnadu, 641105 India \\ ${ }^{2}$ Hindusthan College of Engineering and Technology, Coimbatore, Tamilnadu, 641032 India
}

Received: 4 March 2016

Accepted: 2 August 2016

\begin{abstract}
Progress in semiconductor technology in recent decades has been continuously innovative regarding renewable application. This paper presents fluctuationless output and increased energy captured by a permanent magnet synchronous generator (PMSG) based variable speed wind turbine system (VSWTS) through a composite action of peak power tracking (PPT) controllers in a closed-loop control of turbine speed and boost converter. Though the sensorless control of tip speed ratio (TSR) is preferred at most, incorporation of the high-speed digitized wind gauge replaces the complexity in the closed-loop drive of the turbine generator. The proposed concept includes control over solid-state converters (SSC) to eliminate switched-mode harmonics and thus DC link voltage is maintained at all levels. Fluctuations on the load side can be eliminated with a pulse width modulation (PWM) inverter. The circuit simulation proclaims PMSG voltage and boost voltage for different wind velocities to ensure real power control through optimal wind turbine speed and reactive power control through stabilized output voltage. Our investigation was performed on a $0.5 \mathrm{~kW}$ wind turbine generator and converter module to ensure the synchronized reactive power control at both SSC stages. Comparative test results were taken pertaining to the above discussion, which validates the performance of the proposed system in its typical area of application.
\end{abstract}

Keywords: permanent magnet synchronous generator, peak power tracking, solid-state converter, tip-speed ratio, wind turbine system

\section{Introduction}

Today the greatest global needs include the acquisition of more affordable, sustainable, clean, and natural sources of electricity since the extraction process when generating power using fossil fuels not only stimulates cost-dependency of domestic and imported fuels but also creates drastic pollution and contamination leading to $\mathrm{CO}_{2}$ emissions. Among the natural resources of electricity,

*e-mail: pathyeee@yahoo.co.in wind power is a commercially proven and rapidly growing power generator that provides clean and cost-effective electricity. The International Energy Agency (IEA) has determined that $18 \%$ of global power will be sponsored by wind by 2050 ; that figure is $2.6 \%$ today [1-6].

Most wind turbines today use a variable speed drive system. As its reliability overcomes the fixed speed operating wind turbine by its extra energy capturing ("real power"), improvements in power quality, gearless mechanisms, and thereby fault rates are reduced. Also, the fixed speed wind turbine cannot operate at higher efficiencies across a range of wind speeds [7-8]. In 
PMSG, the provision of a non-winding permanent magnet rotor requires no external stimulus. The absence of a magnetizing current to create an air gap flux and the property of self-excitation makes more attractive the variable speed operation of a wind turbine system. Overall efficiency, the power factor, and - by its huge application - PMSG in large part replaces asynchronous generators in the field [9-10].

VSWTS requires an exemplary control circuitry in order to extract maximum possible power at all intervals of time [11]. PPT is the most popular control strategy today for harvesting large amounts of power from renewables [12]. The classification includes power signal feedback (PSF), in which prior knowledge of a turbine system and wind speed is required to create a prediction-based look-up table. The hill-climbing search (HCS) algorithm is another method, where the clearance is not marked because of its inability to track peak power for abruptly varying wind conditions [13-15]. In the TSR method, although earlier reviews point out the investment cost in its establishment and installation, as a comparison accuracy in achieving huge power has been increased at most in real time, the manifestation of this meticulous method can be achieved with the help of an adaptive high-efficiency digitized wind gauge, and the clearance graph will be yielded during its retaliation. The captured power has to be controlled and stabilized in a series of execution circuits for its ideal output. The stages include rectification, boost conversion, and inversion. Without these SSCs, the direct-drive variable speed operation cannot be accomplished.

This paper proposes a mechanism that delivers less fluctuating output through the composite action of peak power tracker without any torsional oscillations at the output. Also, in this proposed strategy an anti-ripple content is derived proportional to the ripple magnitude for buffering the pulsations between the giant converters (boost converter and inverter).

The PPT action includes:

1. Enhancing real power by controlling the turbine speed.

2. Balancing the reactive power by adjusting the duty cycle of the boost converter.

In the sections that follow, this paper first introduces the importance of renewable energy, the variable speed operation of a wind turbine system, PMSG, and its reliability. A core survey is followed by the characteristics of a wind turbine system and converter topologies. Then the protocol shows the composite control of converters for real and reactive power output with configured duty cycle ratios. Experimental validation is presented in results and discussion to examine the proposed result compared with the conventional method (TSR) under fluctuating wind conditions. Finally, we conclude with a synoptic outline of the main points.

\section{Critical Survey to the Core}

Tan et al. proposed an auto-regressive statistical model injecting the PMSG stator frequency as a source of generator output, which is non-sensor based maximum power point tracking (MPPT) [16]. Here a forecast is made for the wind speed at various time intervals, and a prediction-based look-up table is generated. An accepted level of wind speed can be captured, but the complexity in computation adds difficulty to the design of controllers. Real-time implementation needs a huge survey of the wind as predicted data.

Haque et al. described a control strategy for peak power traction in the PMSG direct drive [17]. The closed loop for wind turbine speed control is done without a speed sensor. A comparison is made between turbine torque and generator torque and the control of error signal formed between the two is suppressed and hence the system is stabilized. The determination of reference torque and reference direct current from the generator speed creates complexity in accuracy for tracking peak power and as this method has no speed sensor the achievement of shaft speed to the abruptly varying wind speed will be relatively delayed.

Uehara et al. reported a problem in the output power fluctuations of the variable speed wind turbine system VSWTS [18]. For the variable speed operation of a wind turbine system, the pitch angle control is a primary function, but during high wind velocities the blade has to withstand stress that must be mitigated. The large variations of the blade angle also result in low energy yield, which can also be controlled using coordinated control methods (pitch angle and DC link). A separate chopper circuit is accessed for DC link voltage maintenance, which adds complexity to the system.

Bhende et al. proposed a control strategy for effective energy management for a standalone VSWTS system by keeping the DC link voltage at its reference value and balancing terminal voltage at the load side with the implementation of a PWM inverter [19]. The electric torque pulsations are also mitigated in an unbalanced load scenario. The paper did not discuss real power management, but instead additional sources have been revealed to keep DC link voltage constant between the giant converters.

Li et al. compared the conventional methods with novel current vector control methods to extract maximum power with the help of speed controllers and powerlimiting controllers [20]. A virtual lookup table is instead manipulated in conventional methods, which also result in disturbances of DC link voltage output when there is a gusty wind.

Kotti et al. proposed a control strategy that mitigates the double-line DC link ripples [21]. Also, they have compared various MPPT Techniques such as TSR control, PSF control, and HCS. An attempt is made to overcome existing deviations in tracking of power by cubic curve formulae. But the virtually formed load curves will fail in its attempt to follow the optimum operating point at its maximum.

The replication of the above core survey innovates the design and development of sophisticated control strategies, (composite PPT I and II) that overcomes today's standards by means of energy efficiency and economy. 


\section{Scenarios in Wind Turbine Systems}

The principle mechanism of a wind turbine is to convert the kinetic energy of the wind into successive cyclic rotational energy and thereby to act as a prime mover source of PMSG to grant electrical energy while the energy available for conversion mainly depends on the velocity of the wind and swept area of the turbine.

The PMSG-based VSWTS and its projection toward the control of a turbine shaft and converter through composite actions I and II are shown in Fig. 1.

Turbine power is given by [22]

$$
\mathrm{P}_{\mathrm{t}}=\mathrm{P}_{\mathrm{w}} \mathrm{XC_{ \textrm {p } }}
$$

Kinetic energy of mass, $E=\frac{1}{2} m \mathrm{~V}^{2}$

Power in wind, $\mathrm{P}_{\mathrm{w}}=\frac{d E}{d t}=\frac{1}{2} \mathrm{~V}^{2} \frac{d m}{d t}$

(Or)

$$
\mathrm{TSR}, \lambda=\frac{\text { Blade } \text { Tip Speed }}{\text { Wind Speed }}=(\operatorname{rpm} \times \pi \times D) / 60
$$

$$
\lambda=\frac{\Omega \mathrm{R}_{\mathrm{b}}}{\mathrm{V}}
$$

No wind turbine can convert more than $59 \%$ of Kinetic energy of the wind into mechanical energy, which is called the Betz limit, and it is the theoretical maximum efficiency termed as power coefficient $\mathrm{C}_{\mathrm{p}}$ [22].

$$
\mathrm{C}_{\mathrm{p}(\text { maximum })}=0.59
$$

But due to the incorporation of various engineering requirements, the real-time practical limit lies between 0.35-0.45 for a best-designed wind turbine. Optimum power delivered by a turbine rotor is given by

$$
\begin{gathered}
\mathrm{P}_{\mathrm{t}(\mathrm{opt})}=\frac{1}{2} \rho \mathrm{A}\left(\Omega_{\mathrm{opt}} \mathrm{R}_{\mathrm{b}} / \lambda_{\mathrm{opt}}\right)^{3} \mathrm{C}_{\mathrm{p}} \\
\mathrm{P}_{\mathrm{t}(\mathrm{opt})}=\mathrm{K}_{\mathrm{opt}} \mathrm{X}\left(\Omega_{\mathrm{opt}}\right)^{3}
\end{gathered}
$$

...where

$$
\mathrm{K}_{\mathrm{opt}}=\frac{1}{2} \rho \mathrm{A}\left(\mathrm{R}_{\mathrm{b}} / \lambda_{\mathrm{opt}}\right)^{3} \mathrm{C}_{\mathrm{p}}
$$

Optimum Torque is given by

$$
\mathrm{T}_{\mathrm{t}(\mathrm{opt})}=\mathrm{K}_{\mathrm{opt}}\left(\Omega_{\mathrm{opt}}\right)^{2}
$$

From Equation (9) it is understood that maximum power of a turbine can be harvested only when it is operating at maximum power coefficient. Also, the turbine rotor speed is to be continuously triggered for various velocities to keep a constant TSR $\left(\lambda_{\text {opt }}\right)$. Power coefficient also represents the fraction of power captured by the wind [23], which is expressed in (11).

$$
C_{p}=\frac{1}{2}\left(\lambda-0.022 \beta^{2}-5.6\right) \mathrm{e}^{-0.17 \lambda}
$$

Power coefficient is the function of $\lambda$ and $\beta$, as shown in Fig. 2. The variation in the pitch angle of the blade changes the operating point of the power coefficient, and hence the output power is controlled. During normal operation the blade pitch adjustment with the rotational

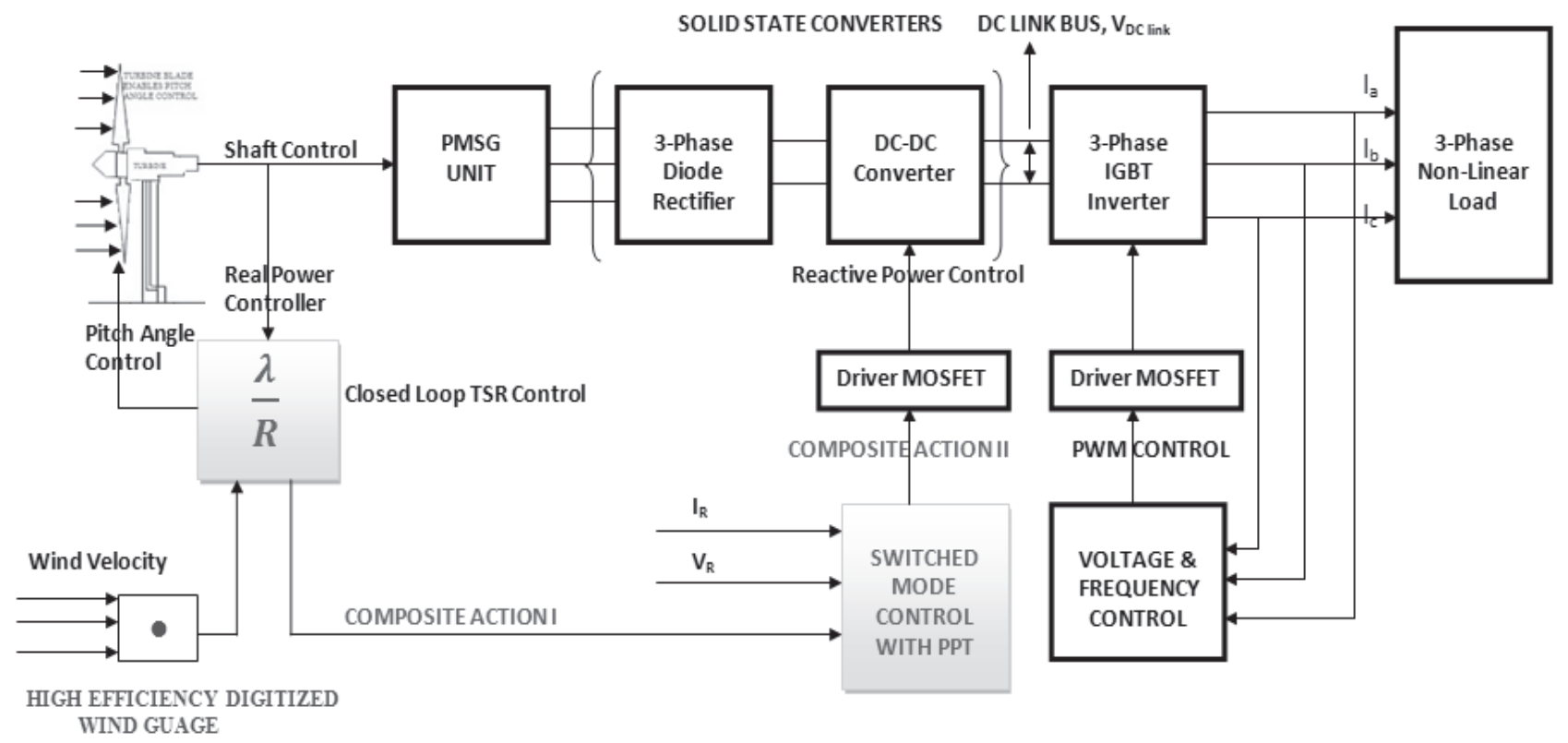

Fig. 1. Control structure of a PMSG-based variable-speed wind turbine system. 


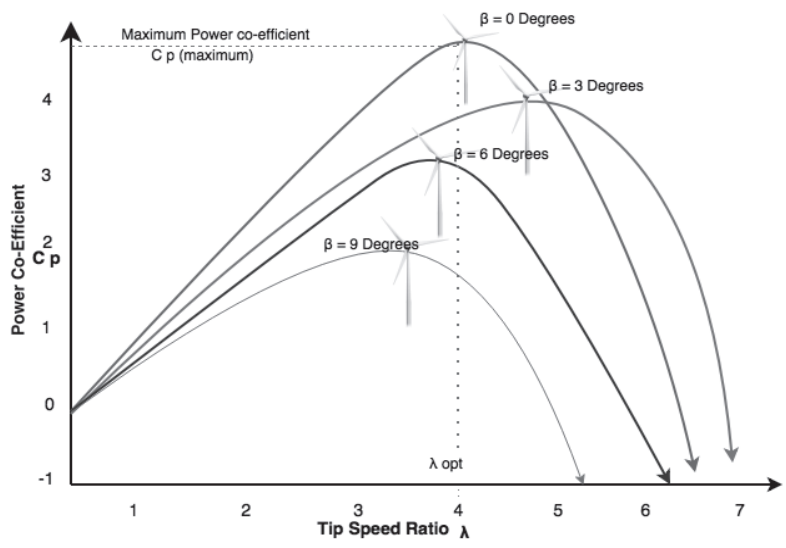

Fig. 2. Power coefficient $C_{p}$ vs. tip speed ratio $\lambda$.

speeds are approximately predicted as $\beta=6-10 \mathrm{deg} / \mathrm{sec}$ (or) $0.09-0.17 \mathrm{rad} / \mathrm{sec}$. In order to keep the TSR constant, the optimum values of turbine speed and pitch angle for various wind velocities are to be predicted and determined.

A set of turbine reference speeds for various wind velocities is obtained from expression (5), and thereby mechanical rotor power as the function of various rotor speeds is determined. From Table 1 it is clear that there is always a matching turbine rotor speed $(\Omega)$ for proportional variable wind speed $(\mathrm{V})$, which produces optimal power [17]. Peak power can be harvested at all times if it is able to follow the optimum values.

\section{Modeling of PMSG}

PMSG does not require magnetizing current for rotor excitation and hence higher efficiency than asynchronous categories. Also, there is no brush and slip ring assembly indicating feasible construction and repair. The core nature imposes safety issues; the torque MMF and flux combines vectorially, which leads to higher air gap densities. Voltage and torque equations of PMSG are given by [24-25]

$$
\frac{\mathrm{d}}{\mathrm{dt}} \mathrm{i}_{\mathrm{d}}=\frac{1}{L d} \mathrm{~V}_{\mathrm{d}}-\frac{R}{L d} \mathrm{i}_{\mathrm{d}}+\frac{L q}{L d} \omega_{\mathrm{r}} \cdot \mathrm{i}_{\mathrm{q}} \cdot \mathrm{P}
$$

Table 1. Proportional turbine speeds for various wind velocities.

\begin{tabular}{|c|c|c|c|}
\hline $\begin{array}{c}\text { Mechanical } \\
\text { power }(\mathrm{PU})\end{array}$ & $\begin{array}{c}\text { Wind Speed } \\
(\mathrm{m} / \mathrm{s})\end{array}$ & $\begin{array}{c}\text { Turbine Speed } \\
\left(\Omega_{\mathrm{opt}}\right)\end{array}$ & $\begin{array}{c}\text { TSR } \\
\left(\lambda_{\mathrm{opt}}\right)\end{array}$ \\
\hline 0 & $\mathrm{~V}_{1}$ & $\Omega_{1}=\left(\mathrm{V}_{1} \lambda / \mathrm{R}\right)$ & $\lambda_{\mathrm{opt}}$ \\
\hline 0.2 & $\mathrm{~V}_{2}>\mathrm{V}_{1}$ & $\Omega_{2}=\left(\mathrm{V}_{2} \lambda / \mathrm{R}\right)$ & $\lambda_{\mathrm{opt}}$ \\
\hline 0.4 & $\mathrm{~V}_{3>} \mathrm{V}_{2}$ & $\Omega_{3}=\left(\mathrm{V}_{3} \lambda / \mathrm{R}\right)$ & $\lambda_{\mathrm{opt}}$ \\
\hline 0.6 & $\mathrm{~V}_{4} \mathrm{~V}_{3}$ & $\Omega_{4}=\left(\mathrm{V}_{4} \lambda / \mathrm{R}\right)$ & $\lambda_{\mathrm{opt}}$ \\
\hline 0.8 & $\mathrm{~V}_{5}>\mathrm{V}_{4}$ & $\Omega_{5}=\left(\mathrm{V}_{5} \lambda / \mathrm{R}\right)$ & $\lambda_{\mathrm{opt}}$ \\
\hline \multicolumn{4}{|c|}{$\Omega_{5}>\Omega_{4}>\Omega_{3}>\Omega_{2}>\Omega_{1}$} \\
\hline
\end{tabular}

$$
\begin{gathered}
\frac{\mathrm{d}}{\mathrm{dt}} \mathrm{i}_{\mathrm{q}}=\frac{1}{L q} \mathrm{~V}_{\mathrm{q}}-\frac{R}{L q} \mathrm{i}_{\mathrm{q}}+\frac{L d}{L q} \omega_{\mathrm{r}} \cdot \mathrm{i}_{\mathrm{d}} \cdot \mathrm{P}-\frac{\lambda a \cdot P \cdot \omega r}{L q} \\
\mathrm{~T}_{\mathrm{e}}=1.5 \mathrm{P}\left[\lambda_{\mathrm{a}} \mathrm{i}_{\mathrm{q}}+\left(\mathrm{L}_{\mathrm{d}}-\mathrm{L}_{\mathrm{q}}\right) \mathrm{i}_{\mathrm{d}} \mathrm{i}_{\mathrm{q}}\right]
\end{gathered}
$$

Dynamic equation of PMSG is given by

$$
\frac{\mathrm{d}}{\mathrm{dt}} \omega_{\mathrm{r}}=\frac{1}{J}\left[\mathrm{~T}_{\mathrm{e}}-\mathrm{T}_{\mathrm{g}}-\mathrm{f} \omega_{\mathrm{r}}\right]
$$

\section{Converter Topology}

The output of the wind-powered PMSG cannot be delivered directly to the bus bar or load. As stated in section I, three execution stages are there for stabilization or power smoothing.

\section{Switched Mode Converters}

The output of the PMSG produces variable voltage with variable frequency due to the variation in wind speed. The uncontrolled switches in the rectification stage convert $3 \phi$ fluctuated AC from the PMSG to variable $\mathrm{DC}$, considering both commutation angle and inductance as negligible. The peak value of voltage and current are expressed as in [24]

$$
\begin{aligned}
V_{R} & =\frac{3 \sqrt{3}}{\pi} V_{d} \\
I_{R} & =\frac{\pi}{2 \sqrt{3}} I_{q}
\end{aligned}
$$

The active switch in the second stage of conversion is fired appropriately to produce saturated output. Also, the duty cycle is triggered along with adjacent components to reduce the DC link voltage ripples. The output voltage of the DC-DC boost converter is given by [24]

$$
\mathrm{V}_{\mathrm{o}}=\frac{\mathrm{V}_{\text {in }}}{1-\delta}=V_{\text {in }}\left(\frac{\mathrm{T}}{\mathrm{T}-\mathrm{T}_{\mathrm{ON}}}\right)
$$

\section{PWM Inverter}

The three-phase IGBT inverters are delineated with PWM driving signals, where the potential drop due to floating load and frequency variations are mitigated. Also, the closed loop controllers are able to derive substantial amplitude of voltage in order to quash the harmonics. Hence, at this stage the voltage is controlled in terms of magnitude and frequency. The potential output of a $3 \phi$ PWM inverter in root mean square (RMS) value is given by [26]

$$
\mathrm{V}_{\mathrm{rms}}=V_{\text {in }}\left[\sum_{k=1}^{2 p u l} \delta_{k} \frac{1}{\pi}\right]^{1 / 2}
$$

$\delta_{\mathrm{k}}-$ width of $\mathrm{k}^{\text {th }}$ pulse. 


\section{Materials and Methods}

\section{Evoked Control Strategies}

\section{Existing PPT Algorithms}

The evolution of VSWTS has innovated the design of various PPT techniques toward increased energy capture. Much research has been put forth, and literature has been surveyed across the globe to overcome the drawbacks of the existing system. The HCS method of PPT incorporates the search-remember-reuse concept by comparing instant power with the power of the previous step at every interval of time. The boost factor of the active switch has to be enhanced if the instant power is maximum and reduced if it reciprocates. Due to inertia in case of WECS, clearance cannot be achieved for abruptly changing wind conditions. In the PSF method, a prediction-based look-up table is created for maximum power at all wind speeds. The algorithm compares the maximum power for particular wind speed with the reference power of the look-up table for the same wind speed. The error signal drives the control algorithm of the active switch for optimized output. The system requires prior knowledge of turbine characteristics and wind speed, which is considered its drawback.

\section{Identity of Composite PPT I}

TSR is a widely accepted concept of energy capture from a wind turbine. Generally, if the turbine rotor rotates slowly, it allows the wind to pass unperturbed between the blade gap. If the rotor rotates rapidly, it appears to be a hindrance and creates a large amount of drag. The necessity of promoting optimal rotor efficiency results in the design of a wind turbine to match the angular velocity of a rotor dovetailing to wind change. A scrupulous wind gauge is used here to adjoin the action of peak power controller for composite action I. The multi-measurement tool provides a ball-bearing resulting in accuracy at all velocities. Console updates at every fraction of a second, and marking the calibration assessment of IEC and MEASNET enhances its stability to the standard. Systemic wind speed is dead set by the function of frequency.

\section{Wind Velocity $=$ Position of Tilt X Frequency X Offset}

The digital gauge measures wind speed, and the instant turbine speed is computed from the digitizer. From the obtained parameters, TSR is thus calculated compared with the system TSR, which is the reference value procured from the wind turbine data. The error signal drives the closed loop control algorithm to enhance and diminish the speed of the turbine shaft through the pitch angle control, which is the action of composite PPT I. It is the juncture where real power can be harvested in a fraction.

The algorithm has to meet this meticulous point at which the change in speed of the turbine blade tip is highly proportional to the change in wind speed:

\section{$\frac{\text { Change in turbine blade tip speed }}{\text { Change in wind speed }}=$ zero}

Hence wind velocity at every instant of time will react with the turbine speed to make TSR constant, since the speed of the wind is incorrigible by nature; turbine speed has to be adjusted in real time for the ideal harvesting of maximum power.

\section{Identity of composite PPT II}

The active switch plays a vital role in the composite PPT II. In the second stage of conversion, IGBT is fired appropriately to produce constant DC output voltage. Also, the duty cycle is triggered along with adjacent components to reduce the DC link voltage ripples, whereby the second stage of PPT is harvested. The DC link capacitor couples the two giant converters and acts as a buffering point of the transient pulsating signals at the converter end. The appropriate triggering of the active switch balances the DC link voltage at all levels. During high wind velocities turbine speed is controlled and real power can be modulated; during low wind velocities, the reactive power can be controlled by the converters, which are shown in Fig. 3. So along with PPT, DC link ripples also are reduced by deriving a differential voltage against the ripple and suppressing the same. The duty cycle ratios are generally expressed as in (20):

$$
\begin{aligned}
& \frac{\mathrm{V}_{\mathrm{DC}}}{\mathrm{V}_{\mathrm{R}}}=\frac{\mathrm{T}}{\mathrm{T}_{\mathrm{OFF}}} \\
& \frac{\mathrm{I}_{\mathrm{DC}}}{\mathrm{I}_{\mathrm{R}}}=\frac{\mathrm{T}_{\mathrm{OFF}}}{\mathrm{T}}
\end{aligned}
$$

As the controlled quantities are both $\mathrm{V}_{\mathrm{DC}}, \mathrm{I}_{\mathrm{DC}}$ and ripple factors are mainly due to converter load variations, the duty ratios should be derived with the product of current values as in (22).

$$
\begin{aligned}
& \frac{\mathrm{V}_{\mathrm{DC}} * \mathrm{I}_{\mathrm{R}}}{\mathrm{V}_{\mathrm{R}} * \mathrm{I}_{\mathrm{DC}}}=\left(\frac{\mathrm{T}}{\mathrm{T}_{\mathrm{OFF}}}\right)^{2} \\
& \left.\frac{\mathrm{T}_{\mathrm{OFF}}}{\mathrm{T}}=\sqrt{(} \frac{\mathrm{V}_{\mathrm{R}} * \mathrm{I}_{\mathrm{DC}}}{\mathrm{I}_{\mathrm{R}} * \mathrm{~V}_{\mathrm{DC}}}\right)
\end{aligned}
$$

The duty ratios of the boost converter with the input voltage $\mathrm{V}_{\mathrm{R}}$ from the rectifier output and $\mathrm{V}_{\mathrm{DC}}$ as the output voltage can be rewritten as (24) and (25):

$$
\begin{gathered}
1-\frac{\mathrm{T}_{\mathrm{OFF}}}{\mathrm{T}}=1-\sqrt{(}\left(\frac{\mathrm{V}_{\mathrm{R}} * \mathrm{I}_{\mathrm{DC}}}{\mathrm{I}_{\mathrm{R}} * \mathrm{~V}_{\mathrm{DC}}}\right) \\
\frac{\mathrm{T}_{\mathrm{ON}}}{\mathrm{T}}=1-\sqrt{(}\left(\frac{\mathrm{V}_{\mathrm{R}} * \mathrm{I}_{\mathrm{DC}}}{\mathrm{I}_{\mathrm{R}} * \mathrm{~V}_{\mathrm{DC}}}\right) \\
\left.\mathrm{T}_{\mathrm{ON} \text { (PPT 2) }}=\mathrm{T}-\mathrm{T} \sqrt{\left(\frac{\mathrm{V}_{\mathrm{R}} * \mathrm{I}_{\mathrm{DC}}}{\mathrm{I}_{\mathrm{R}} * \mathrm{~V}_{\mathrm{DC}}}\right.}\right)
\end{gathered}
$$




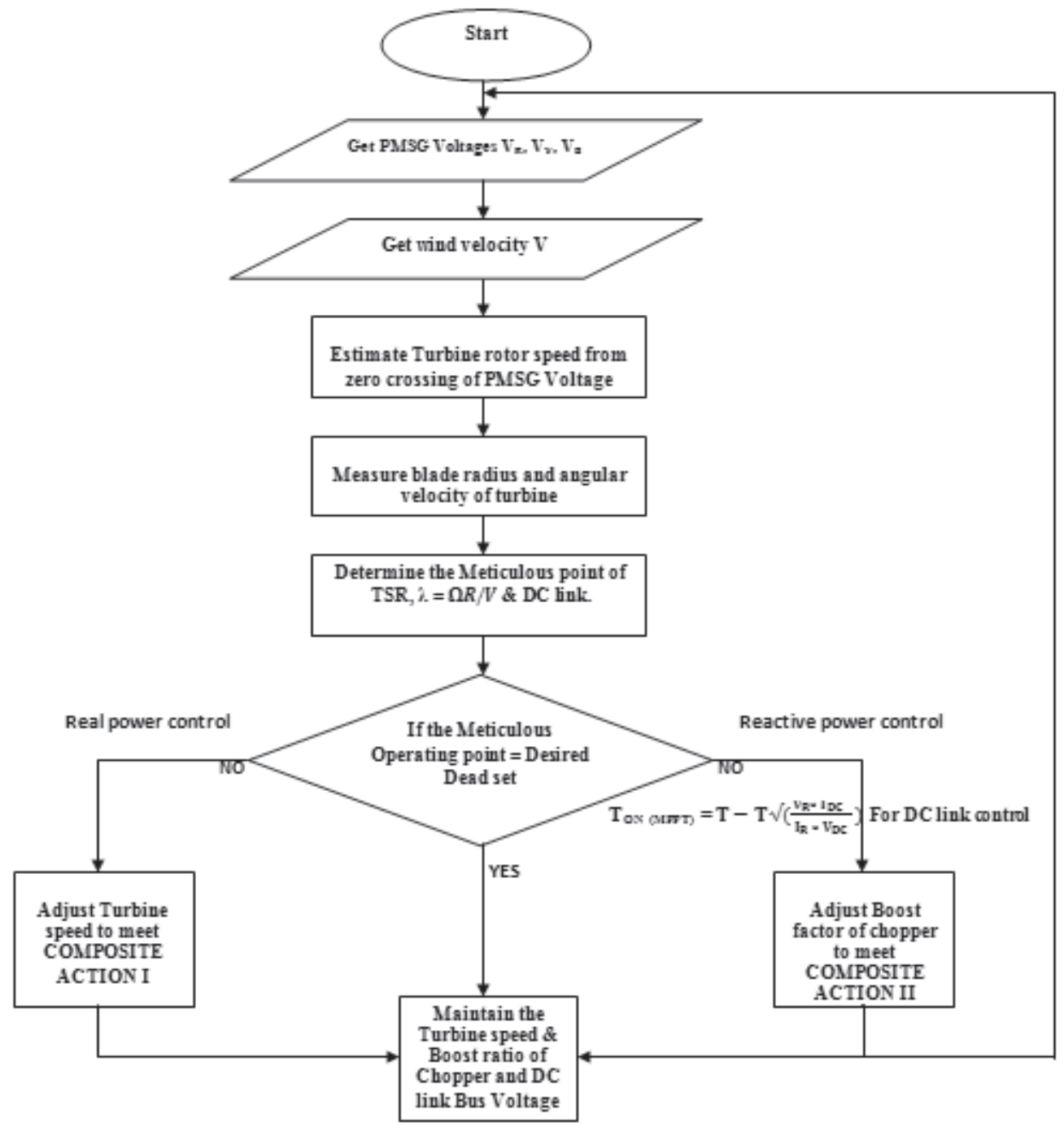

Fig. 3. Control algorithm of composite PPT I and II.

From (26), if it is possible to regulate the duty ratio $\mathrm{T}_{\mathrm{ON} \text { (PPT 2) }}$, reactive power stabilization can be achieved. The accepted value of harmonic content calculated from the system voltage is expressed in (28).

DC link ripples reduction:

$$
\begin{aligned}
& \mathrm{V}_{\mathrm{DC} \text { link }}=\mathrm{V}_{\mathrm{DC}}+\mathrm{V}_{\text {ripple }} \\
& \mathrm{V}_{\text {ripple }}=\mathrm{V}_{\mathrm{DC}} \times \mathrm{Z} \text { Sin } \omega \mathrm{t}
\end{aligned}
$$

$\mathrm{Z}=$ factor of harmonic content

Sin $\omega \mathrm{t}=$ harmonic content

$$
\frac{\mathrm{V}_{\mathrm{R}}}{\mathrm{V}_{\mathrm{OUT}}}=\left(\frac{\mathrm{T}-\mathrm{T}_{\mathrm{ON}(\mathrm{PPT})}}{\mathrm{T}}\right)(1+\mathrm{Z} \operatorname{Sin} \omega \mathrm{t})
$$

A substantial voltage of amplitude $(1+Z \operatorname{Sin} \omega t)$ is developed to suppress the DC link voltage ripples. As wind velocity varies, the PMSG output may vary accordingly, therefore the output current $\left(I_{R}\right)$ and output voltage $\left(V_{R}\right)$ are measured and given as feedback to the composite controller, such that the $\mathrm{ON}$ time $\mathrm{T}_{\mathrm{ON} \text { (PPT 2) }}$ of the active switch is adjusted, and the output power is maximized and stabilized in accordance with the optimum values of power.

\section{Results and Discussion}

\section{Experimentation by Simulation}

The modeled system is constructed through MATLAB/ SIMULINK 2011 software in order to eliminate complexity in the closed-loop drive of the wind turbine system and to enhance the quality of power output from the renewable system. The accounted power rating of the PMSG system is $6 \mathrm{~kW}$, which is used for driving a sensitive load in industrial applications. The technology discussed by means of capturing, converting, and controlling has been incorporated in the SIMULINK model through the power converters and control algorithms as discussed in materials and methods. The sampling time to run the simulation is made in three seconds, since it takes enough time to settle 


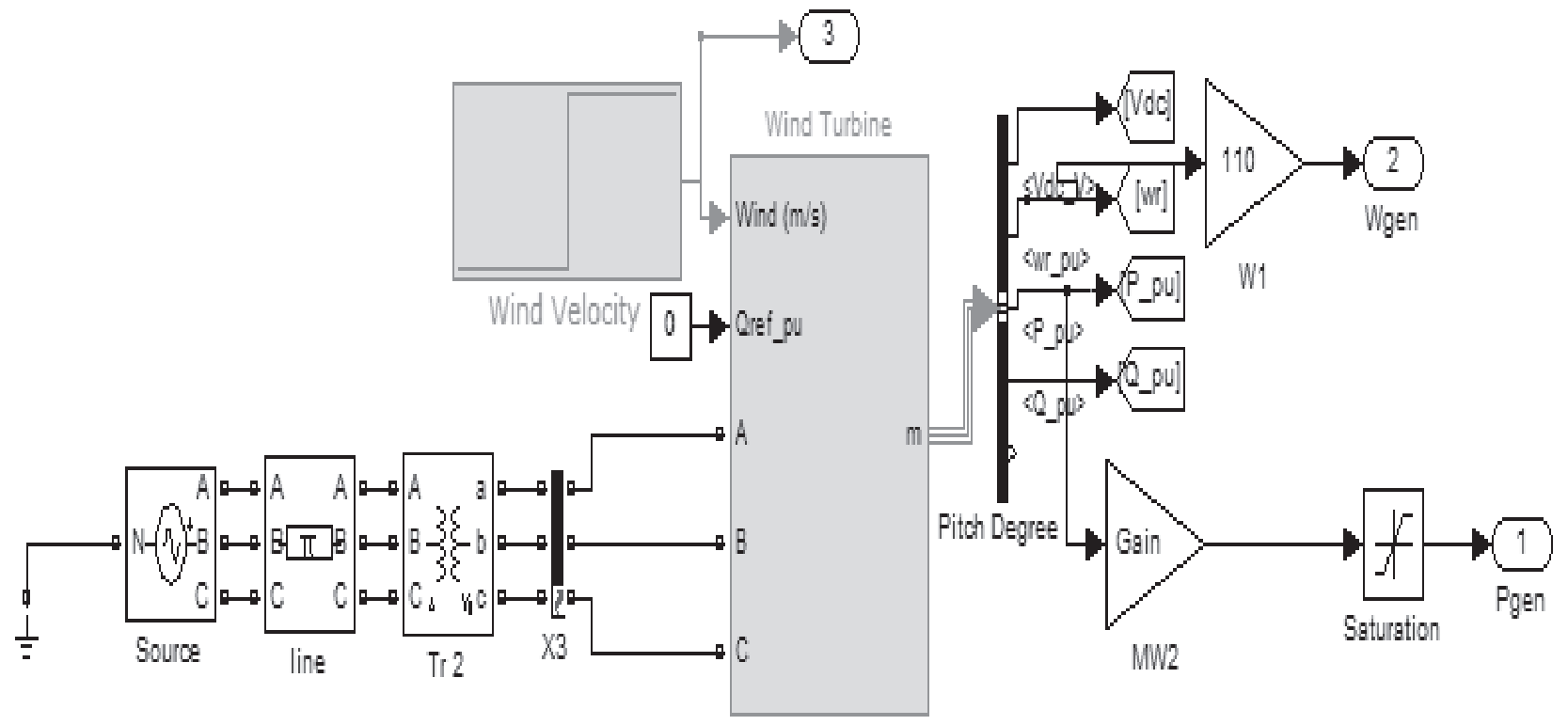

Fig. 4. Model of wind turbine system.

down because of the large power rating of the machine. The response of the entire system is simulated for the step change of wind speed from 6 to $20 \mathrm{~m} / \mathrm{s}$, but for detailed analysis the corresponding changes are noted for 10 to $14 \mathrm{~m} / \mathrm{s}$ as the base speed of wind is $12 \mathrm{~m} / \mathrm{s}$. Fig. 4 shows the drive train model of the wind turbine system where the set value of the wind speed is manipulated. Initially, the system is supposed to run for $10 \mathrm{~m} / \mathrm{s}$ up to 1.5 seconds (Fig. 5a), and hence as the drive train is coupled with a 12 MW PMSG rotor it produces an output voltage of $210 \mathrm{~V}$ (considering a single phase for analysis). The

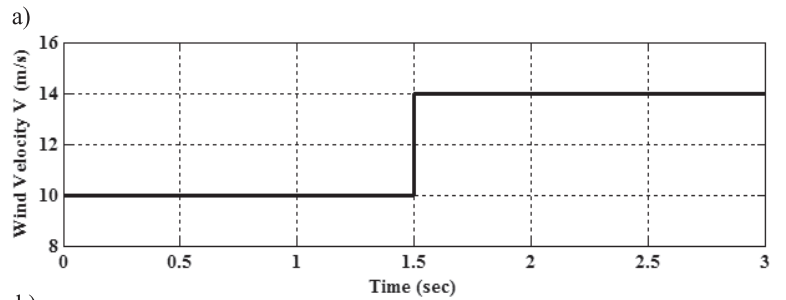

b)

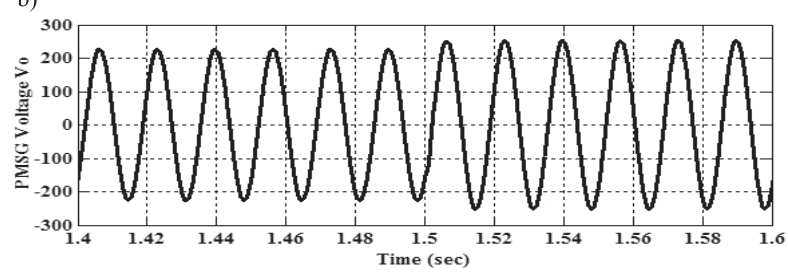

c)

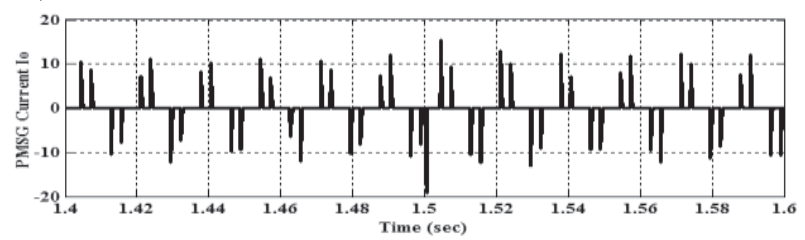

Fig. 5. Response of the system to a step change in wind speed from $10 \mathrm{~m} / \mathrm{s}$ to $14 \mathrm{~m} / \mathrm{s}$ : a) Wind speed, b) PMSG Voltage, c) PMSG Current. turbine speed at this operating point is calculated as $103 \mathrm{rad} / \mathrm{sec}$ and frequency is $49.50 \mathrm{~Hz}$. The TSR is measured as 6.90, which is close to the unit standard 7 of the proposed system (calculated from the swept area of the blade). It is not an issue whether the TSR matches to the standard because every system is configured and modeled to do so, but how fast the action occurs will route to the power-capturing capacity at those fractions of seconds. Since there is always a matching turbine rotor speed for every wind speed [17] (which is calculated from the base value of TSR), the protocol will be such that wind speed is measured using a digitized wind gauge. It is compared with the actual turbine speed through the system (standard) TSR and the generated error will abruptly change the pitch

a)

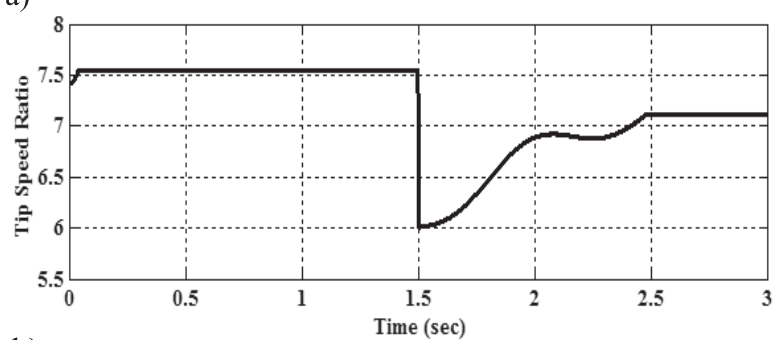

b)

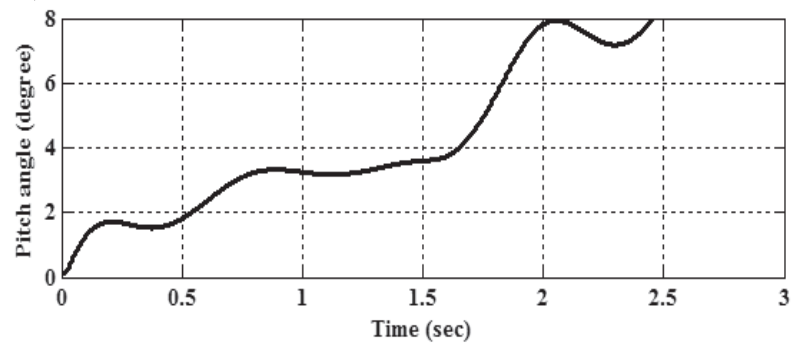

Fig. 6. Tracking system showing a) TSR and b) pitch angle variations without the proposed controller. 
a)

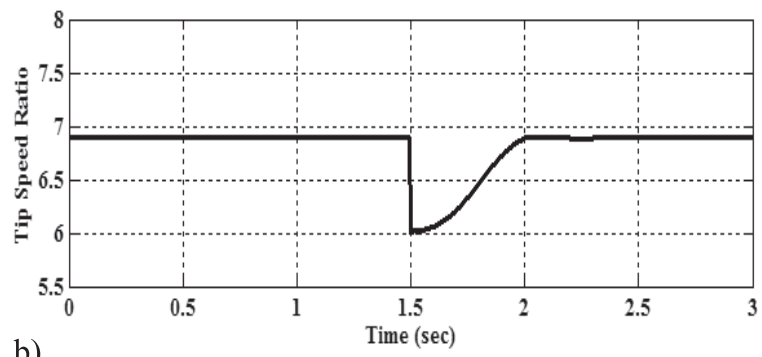

b)

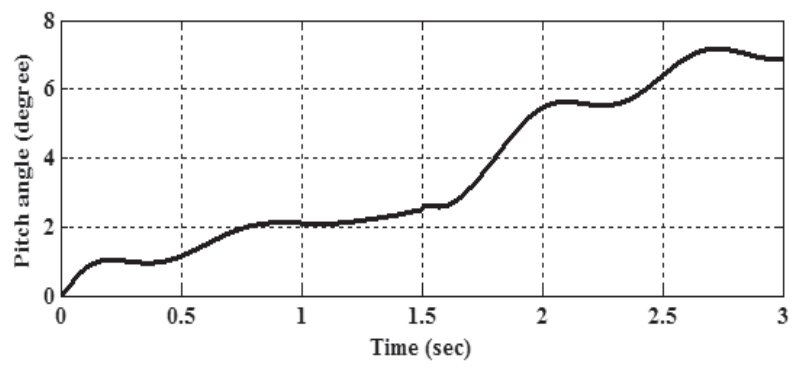

Fig. 7. Tracking system showing a) TSR and b) pitch angle variations with the proposed controller.

angle of the blade within the range of 0.09 to $0.17 \mathrm{rad} / \mathrm{sec}$ to achieve the fixed value of TSR. The real power harvest is completely proportional to the settling of TSR value. The potential and current output at this instant is shown a)

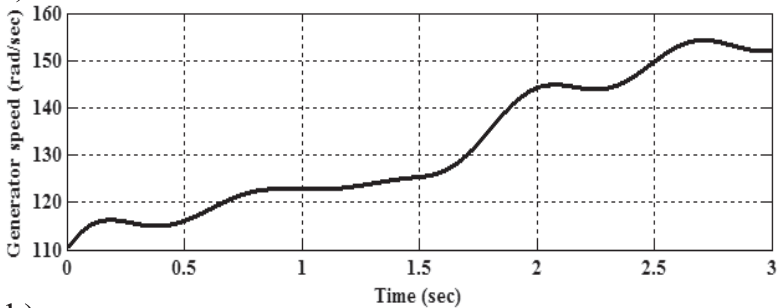

b)

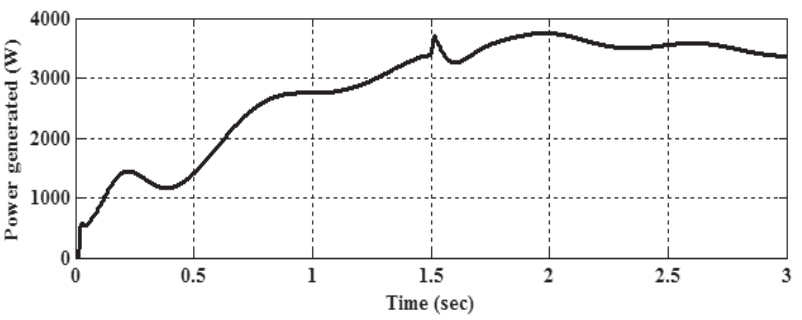

Fig. 8. Tracking system showing a) generator speed b) generated power.

in Figs 5b-c. In this dissemination, based on turbine speed and wind velocity, a cross demonstration is made for the accuracy of TSR in delivering the output power by the proposed system from the existing control strategy, which is shown in Figs 6a-b and 7a-b. The increase in wind velocity from $10 \mathrm{~m} / \mathrm{s}$ to $14 \mathrm{~m} / \mathrm{s}$ takes place at 1.5 seconds,

Table 2. Performance comparison of the proposed system by incorporating composite PPT I and II.

\begin{tabular}{|c|c|c|c|c|c|c|c|c|c|c|c|c|}
\hline \multirow{3}{*}{$\begin{array}{l}\text { Wind } \\
\text { speed } \\
(\mathrm{m} / \\
\mathrm{sec})\end{array}$} & \multicolumn{4}{|c|}{ EXISTING METHOD } & \multicolumn{8}{|c|}{ PROPOSED METHOD } \\
\hline & \multirow{2}{*}{$\begin{array}{c}\text { Turbine } \\
\text { speed } \\
(\mathrm{rad} / \\
\mathrm{sec})\end{array}$} & \multirow{2}{*}{$\begin{array}{c}\text { Power } \\
\text { generated } \\
\text { in } \\
\text { per unit }\end{array}$} & \multicolumn{2}{|c|}{$\begin{array}{l}\text { TSR Optimum } \\
\quad(7.44)\end{array}$} & \multirow{2}{*}{$\begin{array}{c}\text { Turbine } \\
\text { speed } \\
(\mathrm{rad} / \\
\mathrm{sec})\end{array}$} & \multirow{2}{*}{$\begin{array}{c}\text { Power } \\
\text { generated } \\
\text { per unit }\end{array}$} & \multicolumn{2}{|c|}{$\begin{array}{l}\text { TSR optimum } \\
\quad(7.00)\end{array}$} & \multirow{2}{*}{$\begin{array}{l}\text { PMSG } \\
\text { voltage } \\
\text { (Volts) }\end{array}$} & \multirow{2}{*}{$\begin{array}{c}\text { Frequency } \\
\text { of PMSG } \\
\text { voltage } \\
(\mathrm{Hz})\end{array}$} & \multirow{2}{*}{$\begin{array}{l}\text { Potential } \\
\text { of DC } \\
\text { link } \\
\text { Capacitor } \\
\text { (Volts) }\end{array}$} & \multirow{2}{*}{$\begin{array}{l}3 \text { Phase } \\
\text { Inverter } \\
\text { Voltage } \\
\text { (Volts) }\end{array}$} \\
\hline & & & $\begin{array}{l}\text { Obtained } \\
\text { value }\end{array}$ & $\begin{array}{c}\text { TSR } \\
\text { error } \\
\%\end{array}$ & & & $\begin{array}{c}\text { Obtained } \\
\text { value }\end{array}$ & $\begin{array}{c}\text { TSR } \\
\text { error \% }\end{array}$ & & & & \\
\hline 6 & 69 & 0.1101 & 6.67 & 0.77 & 61 & 0.0991 & 6.81 & 0.19 & 147 & 15.5 & 680 & 415 \\
\hline 7 & 84 & 0.1352 & 6.96 & 0.48 & 72 & 0.1251 & 6.89 & 0.11 & 161 & 22.3 & 680 & 415 \\
\hline 8 & 106 & 0.2412 & 7.68 & 0.24 & 84 & 0.154 & 7.0 & 0 & 179 & 30.7 & 680 & 415 \\
\hline 9 & 110 & 0.3621 & 7.08 & 0.36 & 94 & 0.2113 & 6.99 & 0.01 & 193 & 42.0 & 680 & 415 \\
\hline 10 & 125 & 0.6160 & 7.25 & 0.19 & 103 & 0.4269 & 6.90 & 0.10 & 210 & 49.5 & 680 & 415 \\
\hline 11 & 136 & 0.7910 & 7.17 & 0.27 & 111 & 0.7598 & 6.76 & 0.24 & 224 & 58.9 & 680 & 415 \\
\hline 12 & 150 & 0.9751 & 7.25 & 0.19 & 124 & 1 & 6.92 & 0.08 & 240 & 65.5 & 680 & 415 \\
\hline 13 & 161 & 1 & 7.183 & 0.26 & 132 & 1 & 6.80 & 0.20 & 257 & 67.0 & 680 & 415 \\
\hline 14 & 172 & 1 & 7.13 & 0.31 & 144 & 1 & 6.89 & 0.11 & 270 & 71.0 & 680 & 415 \\
\hline 15 & 188 & 1 & 7.26 & 0.18 & 153 & 1 & 6.83 & 0.17 & 292 & 73.2 & 680 & 415 \\
\hline 16 & 202 & 1 & 7.32 & 0.12 & 165 & 1 & 6.90 & 0.10 & 307 & 77.3 & 680 & 415 \\
\hline 17 & 212 & 1 & 7.23 & 0.21 & 177 & 1 & 6.97 & 0.03 & 322 & 79.7 & 680 & 415 \\
\hline 18 & 225 & 1 & 7.25 & 0.19 & 189 & 1 & 7.0 & 0 & 336 & 81.1 & 680 & 415 \\
\hline 19 & 238 & 1 & 7.26 & 0.18 & 198 & 1 & 6.98 & 0.02 & 348 & 84.2 & 680 & 415 \\
\hline 20 & 256 & 1 & 7.42 & 0.02 & 208 & 1 & 6.96 & 0.04 & 360 & 85.0 & 680 & 415 \\
\hline
\end{tabular}




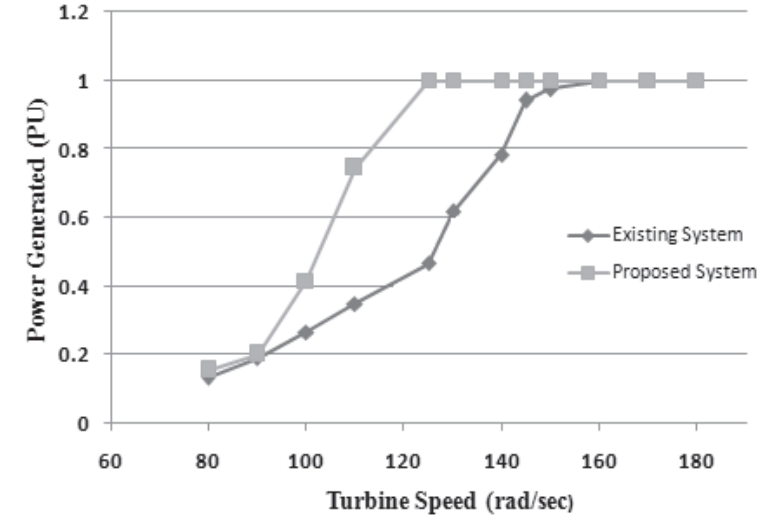

Fig. 9. Cross-comparison of power generated (existing and proposed systems).

and it is the response of the PPT I controller to correlate it with set TSR. The TSR unit standard of the existing system is 7.44 (calculated from the swept area of the blade). Since the system has no wind gauge it has to go with the indirect monitoring of generator torque, turbine torque, and SMC current in order to generate the error signal to drive the generator speed to optimal level for compromising the TSR value (7.44). For measuring DC current it requires a current sensor or current transformer, which is compared with reference current from the reference torque [17]. Because the protocol follows three stages in the sensorless control, the accuracy level at that instant fails to harvest peak power.

But in our proposed system the measurement is made directly using the digitizer, which makes the TSR settle down fast. The error difference between the two cases oscillates the pitch angle to follow the optimal curve. The upshot of the controller in tracking real power (PPT I) is shown in Figs 8a-b. A critical analysis is made at various wind velocities and therefore a statistical chart displaying the TSR error for the existing and proposed system is shown in Table 2. The turbine speed increases in both cases (existing and proposed) with increasing wind velocity, but due to the problem of inertia and complicated inner current control loop of the existing system, it is unable to reach its maximum and thus TSR collapses for a juncture, which replicates the power generated (per unit) at its base speed. Even though the base speed in both cases is $12 \mathrm{~m} / \mathrm{s}$, the existing system fluctuates at a fraction of a second and then attains the actual rating of the machine, which is shown in Fig. 9. Therefore, the action will repeat for every change in wind speed and hopefully peak power cannot be harvested at the miniature points. But this has been eclipsed in our proposed system. Hence the simulation result carried out by the PPT I controller reveals very good steady state and dynamic response in the extraction of real power. The magnitude and frequency of the PMSG voltage are directly proportional to the wind velocity and varies linearly with it.

The hierarchy promotes the fluctuated $\mathrm{AC}$ to the series of converter stages as discussed in materials and

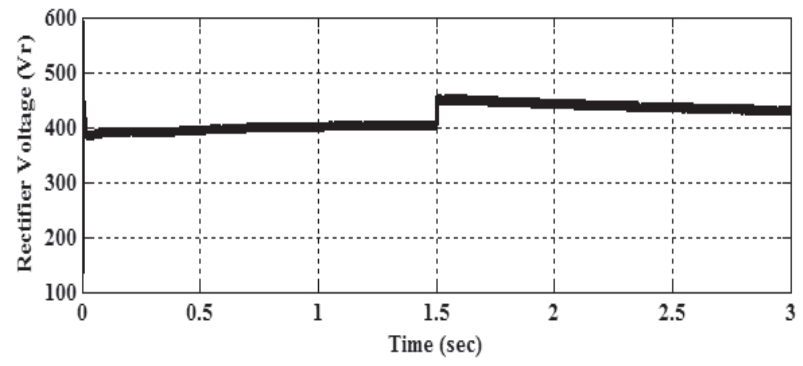

Fig. 10. AC-DC rectified voltage.

methods in order to deliver constant and fixed output to drive the loads. Since the speed of the wind is unreliable and proportionally its dependency voltage fluctuates. The potentially variable PMSG voltage is given as input to the rectifier, which is structured with filter capacitor and which gives the variable DC voltage shown in Fig. 10. The fluctuated DC is stabilized to a constant $680 \mathrm{~V}$ DC through the appropriate triggering of the active switch of the switched mode converter shown in Fig. 11a-d. The closed-loop feedback of PMSG, rectifier, boost converter voltage, and current is taken to derive the $\mathrm{T}_{\mathrm{ON} \text { (PPT 2) }}$ and a substantial voltage of magnitude $(1+\mathrm{Z} \operatorname{Sin} \omega \mathrm{t})$ to deliver a ripple-free DC link voltage and reactive power stabilized output. The DC link capacitor placed between the giant
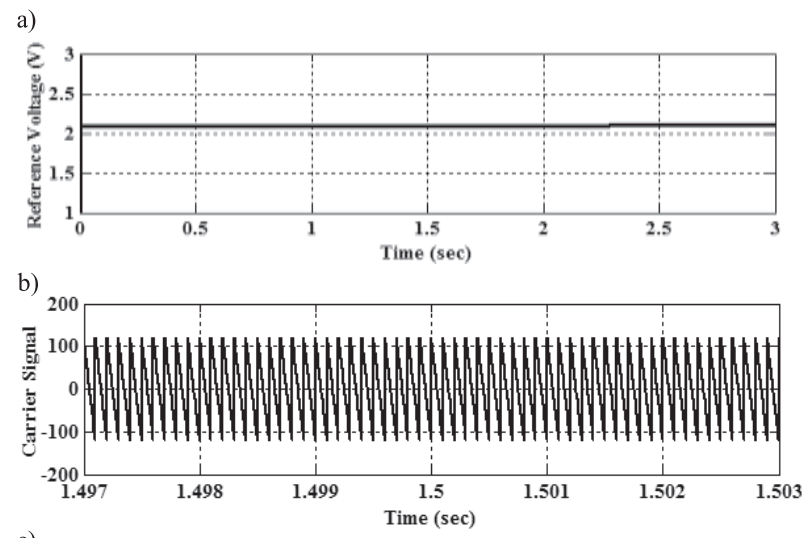

c)

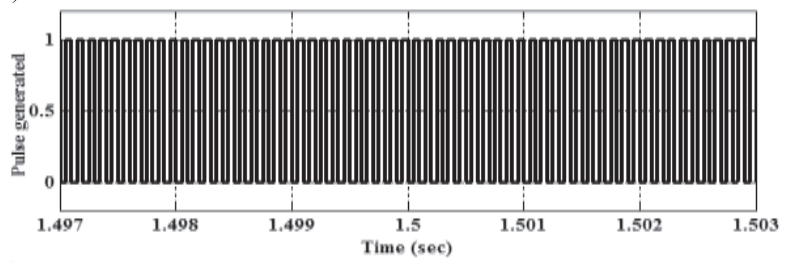

d)

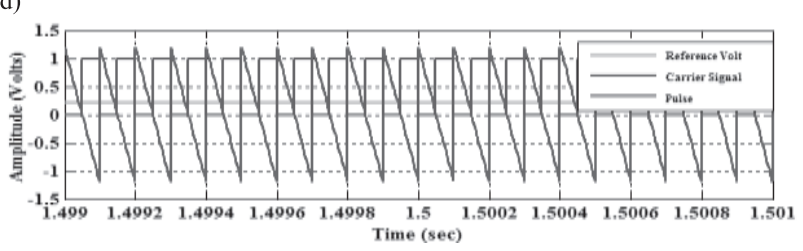

Fig. 11. Triggering signal to the active switch of the boost converter: a) Reference voltage, b) Carrier signal, c) Generated pulse, d) Gating pulse generated from reference and carrier signal. 


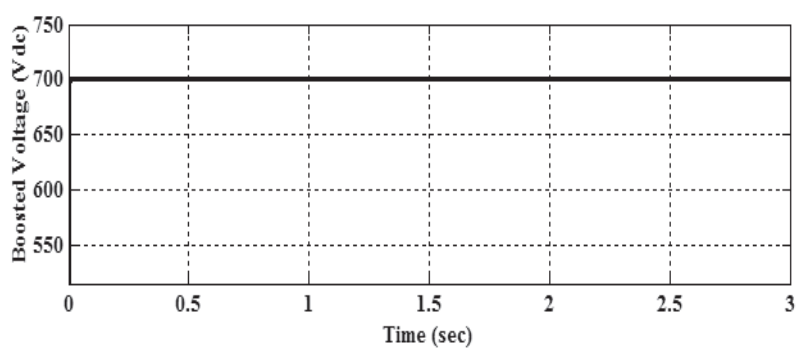

Fig. 12. Ripple-free DC link voltage.

converters balances the DC link voltage, which is shown in Fig. 12. The output of the solid-state DC-DC converter shows that the PPT II controller has come up with a prime response. The DC voltage is given as input to the threephase PWM inverter. Since the load is non-linear, the sudden variation creates voltage disturbances across the inverter and hence the PWM signals are preferred to fire the semiconductor switches of the inverter appropriately and thereby fluctuations at the output in terms of voltage and frequency are mitigated. The firing pulse of the inverter is triggered based on $50 \mathrm{~Hz}$ output frequency, which is shown in Fig. 13a and hence the switching speed depends on the same. The inverter output voltage for all three phases with $120^{\circ}$ phase shift are shown in Figs 13bd. The magnitude indicates the peak value of voltage and Fig. 14 shows the RMS value of the inverter phase A voltage. The instantaneous values of three-phase load voltage and load current are shown in Figs 15-16. The current alone is subject to variations on floating loads and the voltage will always be constant. Hence the protocol

a)

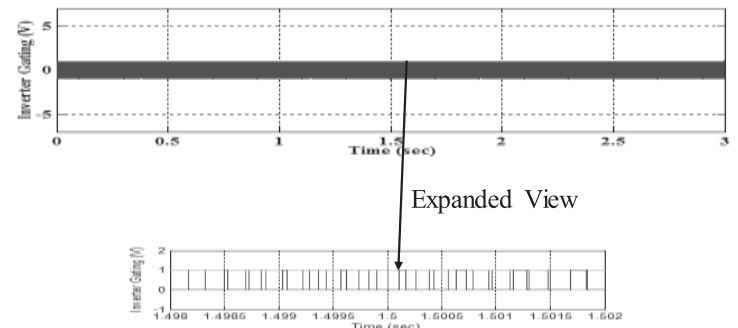

b)

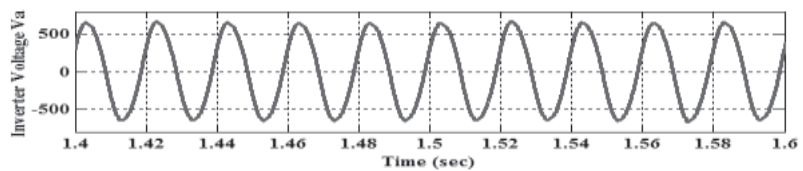

c)

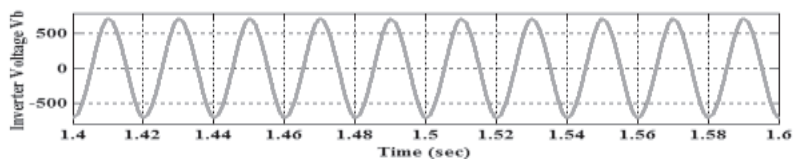

d)

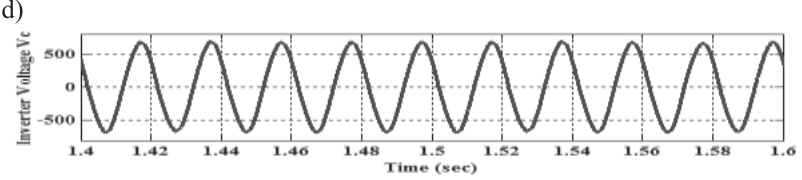

Fig. 13. (a) Inverter gate signal; b), c), d) - inverter three-phase voltages A, B, C. of the entire system ends with the inverter output and its controller works well in its static and dynamic response. The simulation parameter of the energy conversion system is shown in Table 3.

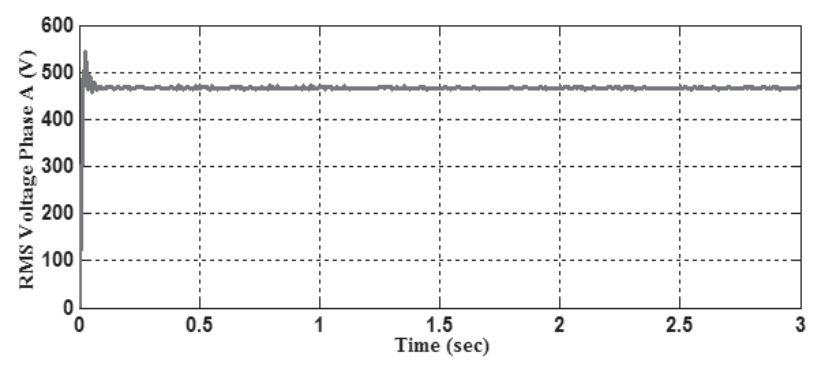

Fig. 14. RMS Value of inverter voltage - phase A.

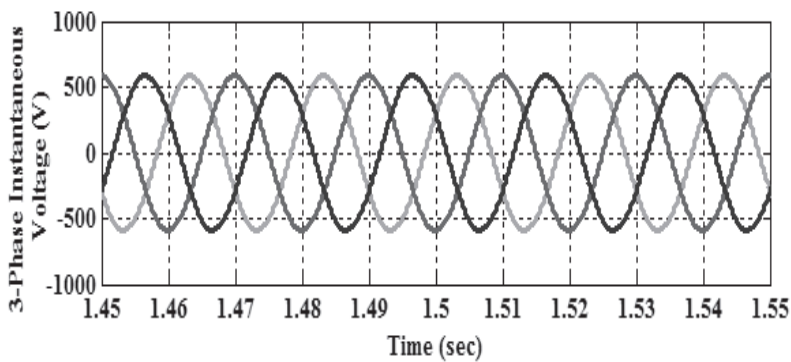

Fig. 15. Instantaneous three-phase load voltage.

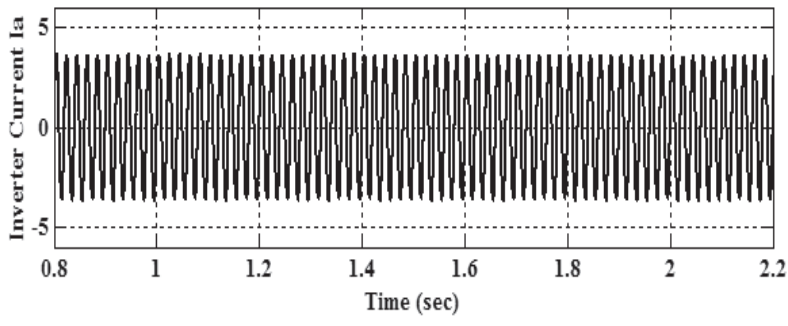

Fig. 16. Instantaneous three-phase inverter current at non-linear load.

Table 3. Design parameters of the energy conversion system.

\begin{tabular}{|c|c|c|c|}
\hline \multicolumn{2}{|c|}{ Wind Turbine } & \multicolumn{2}{|c|}{ PMSG } \\
\hline Air density & $1.23 \mathrm{Kg} / \mathrm{m}^{3}$ & $\begin{array}{l}\text { Number of } \\
\text { phases }\end{array}$ & 3 \\
\hline Swept area & $1.409 \mathrm{~m}^{2}$ & Back EMF & Sinusoidal \\
\hline $\begin{array}{l}\text { Radius of } \\
\text { blade }\end{array}$ & $0.67 \mathrm{~m}$ & Rotor & $\begin{array}{l}\text { Round } \\
\text { rotor }\end{array}$ \\
\hline $\begin{array}{l}\text { Blade } \\
\text { efficiency }\end{array}$ & $0.35 / 0.40$ & $\begin{array}{c}\text { Stator resistance } \\
\text { per phase }\end{array}$ & $0.006 \mathrm{PU}$ \\
\hline $\begin{array}{c}\text { Lift } \\
\text { coefficient }\end{array}$ & 0.85 & Stator inductance & $0.8 \mathrm{mH}$ \\
\hline $\begin{array}{c}\text { Base speed } \\
\text { of wind }\end{array}$ & $10 \mathrm{~m} / \mathrm{s}$ & Pole pairs & 5 \\
\hline $\begin{array}{l}\text { Power } \\
\text { coefficient }\end{array}$ & $\begin{array}{c}\text { Function of } \\
\qquad \lambda, \beta\end{array}$ & Rated torque & $\begin{array}{l}1 \text { Nominal } \\
\text { PU }\end{array}$ \\
\hline
\end{tabular}




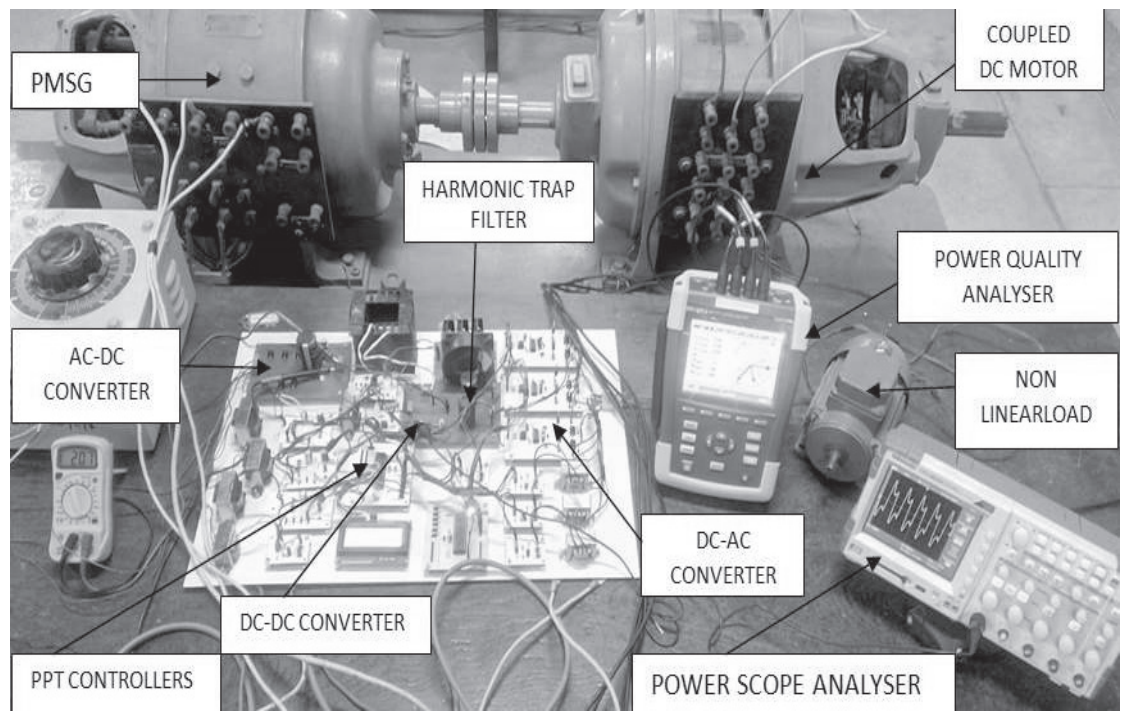

Fig. 17. Test rig platform of PMSG-based WECS.

\section{Experimental Validation by Test Rig}

The proposed closed-loop control algorithm (PPT I and II) is corroborated using a small-scale test rig platform in a laboratory. The principle theory should remain identical as in simulation to that of a practical wind energy conversion system. The machine and converter topology can be synchronized based on the rating of the test rig and accordingly inner current control loop leading to real and reactive power stabilizing. In this regard the proposed dissemination bestowed with the control over turbine speed (real power) and SSC (reactive power), which can be carried out using an outer loop and will remain fixed irrespective of the machine rating. The test rig includes three-phase, $0.5 \mathrm{~kW}$ PMSG with its stator terminal connected to the SSC, which combines a rectifier (six diodes are used in bridge connection) and boost converter (one MOSFET is used as an active switch). The three-phase PWM inverter is connected (six IGBT switches) to the load. The controller is programmed with

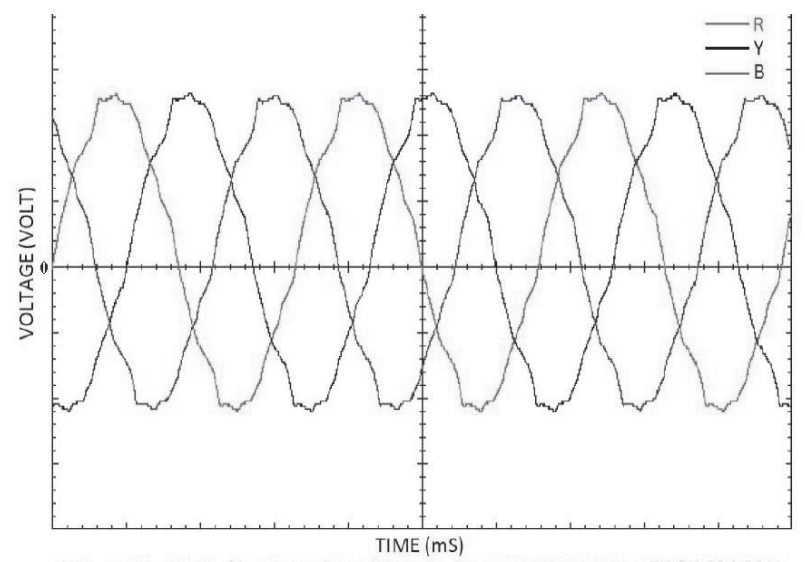

CHA $5 \mathrm{mS} 100 \mathrm{~V} /$ div Period:16429.34uS Frequency:60.867Hz PK-PK:324.00 V CHB $5 \mathrm{~ms} 100 \mathrm{~V} / \mathrm{div}$ Period:16429.34uS Frequency:60.867 Hz PK-PK:324.00 V

Fig. 18. Three-phase PMSG output voltage (power scope result).
PPT algorithm for fast execution of real-time outputs and is looped individually for the converters. A four-pole,

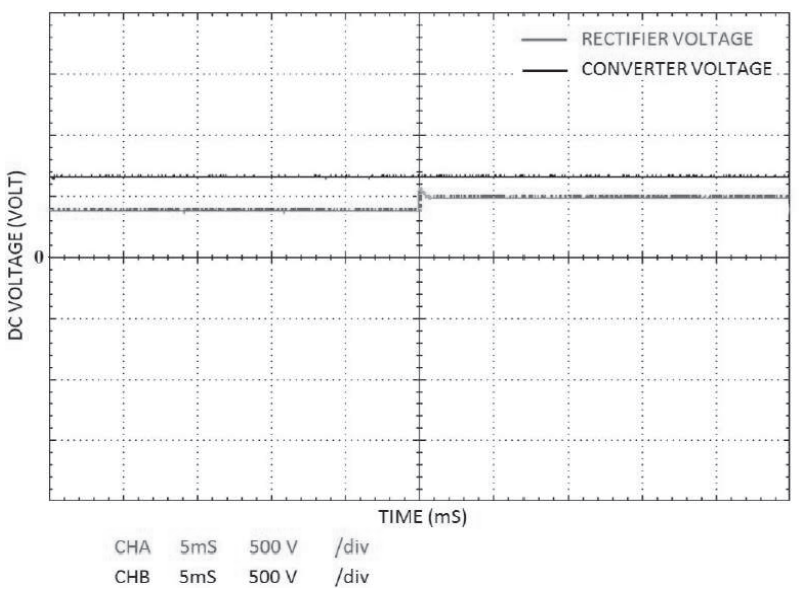

Fig. 19. Rectified and boosted DC voltage (power scope result).

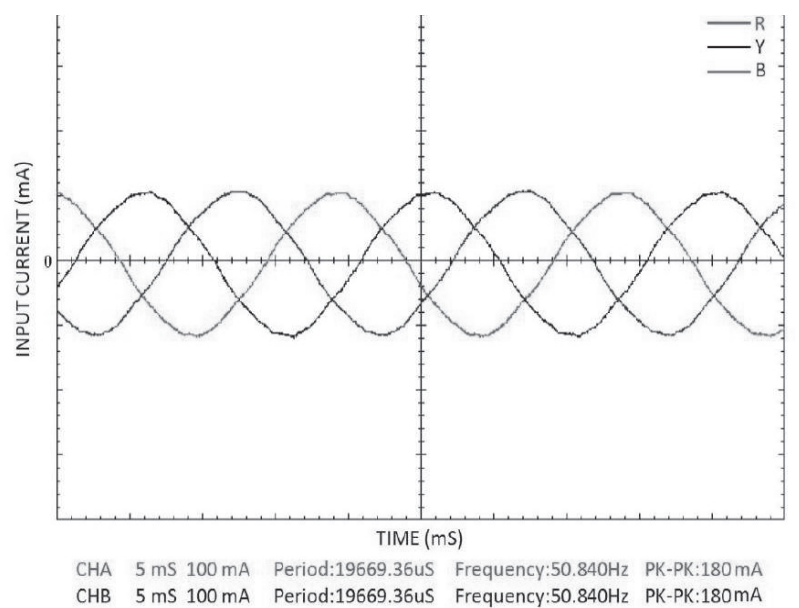

Fig. 20. Three-phase inverter output current (power scope result). 
Table 4. Performance analysis from prototype circuitry.

\begin{tabular}{|c|c|c|c|c|}
\hline $\begin{array}{c}\text { S. } \\
\text { number }\end{array}$ & $\begin{array}{c}\text { Rectifier } \\
\text { voltage } \\
\left(\mathrm{V}_{\mathrm{r}}\right)\end{array}$ & $\begin{array}{c}\text { Boost } \\
\text { converter } \\
\text { voltage } \\
\left(\mathrm{V}_{\mathrm{DC}}\right)\end{array}$ & $\begin{array}{c}\text { 3-Phase } \\
\text { inverter } \\
\text { voltage }\end{array}$ & $\begin{array}{c}\text { Inverter } \\
\text { output } \\
\text { frequency }\end{array}$ \\
\hline 1 & 350 & 678 & 415 & 49.57 \\
\hline 2 & 382 & 680 & 417 & 50.41 \\
\hline 3 & 398 & 679 & 415 & 50.86 \\
\hline 4 & 420 & 681 & 416 & 49.87 \\
\hline 5 & 436 & 678 & 415 & 50.84 \\
\hline 6 & 452 & 680 & 414 & 49.89 \\
\hline 7 & 472 & 681 & 415 & 49.82 \\
\hline 8 & 486 & 680 & 418 & 50.51 \\
\hline 9 & 495 & 677 & 416 & 50.57 \\
\hline 10 & 520 & 680 & 415 & 49.70 \\
\hline & & & & \\
\hline
\end{tabular}

$0.25 \mathrm{HP}$, three-phase induction motor load is connected at the terminal of the PWM inverter, where the load torque remains unchanged regardless of the PMSG output voltage. The experimental setup is thus organized as generation, conversion, control, and driving action as shown in Fig. 17. Here the turbine shaft speed can be varied electrically and the closed loop system (PPT I) acquires the task to generate gate pulse to control the potential of the motor coupled with PMSG. In parallel, the closed loop system (PPT II) acquires the task to control the active switch of boost converter for balancing the reactive power issues. The experimental results and measurements are carried out using a power scope analyzer interfaced with a personal computer, which represents PMSG voltage, rectified and boosted voltage, and inverter current in the corresponding (Figs 18-20). The readings are then charted in Table 4, which is correlated with the simulation result and thereby validation is made for the proposal. Small harmonic trappers (filter capacitor) are used to mitigate the lower-order harmonics to improve power quality. Potential and current transformers are used in the prototype for isolating control and power circuits, and for direct measurement of high voltage and current.

\section{Conclusion}

The control strategy presented for PMSG-based VSWTS has the potential to improve active power output and reactive power stability by incorporating composite PPT controllers. From the response of the TSR curve, it is clear that the controller is working at its maximum in delivering variable peak power output at all wind velocities. The secondary importance given to the SSC for reactive power stabilization and harmonic ripple reduction are validated through the maintenance of ripple-free DC link voltage supported by the anti-ripple content derived from the fundamental component of ripple. Finally, the inverter leg is fired with PWM signals for the controlled three-phase AC voltage in terms of amplitude and frequency. The experimental results (software and core) demonstrate the protocol pertaining to the discussion, and the progression toward this innovation will certainly hope for the best outcome in today's renewable world.

\section{Acknowledgements}

The authors would like to thank the Government College of Technology, Coimbatore, for the information provided regarding a weather monitoring station (WIND GAUGE) to carry out this innovative research.

\section{Nomenclature}

$\mathrm{E}=$ Kinetic energy in joules

$\rho=$ Air density $\left(\mathrm{Kg} / \mathrm{m}^{3}\right)$

$\mathrm{C}_{\mathrm{p}}=$ Power coefficient

$\mathrm{D}=$ Diameter of wind turbine blade $(\mathrm{m})$

$\mathrm{R}_{\mathrm{b}}=$ Radius of wind turbine blade $(\mathrm{m})$

$\mathrm{V}=$ Wind velocity $(\mathrm{m} / \mathrm{s})$

$\mathrm{P}_{\mathrm{w}}=$ Power in the wind (watts)

$\mathrm{P}_{\mathrm{t}}=$ Power captured by turbine (watts)

$\mathrm{A}=$ Swept arc in $\mathrm{m}^{2}$

$\mathrm{m}=$ Mass in $\mathrm{kg}$

$\Omega=$ Turbine speed in Radian/sec

$\mathrm{T}_{\mathrm{t}}=$ Turbine torque $(\mathrm{Nm})$

$\lambda=$ Tip speed ratio (TSR)

$\beta=$ Pitch angle in radian $/ \mathrm{sec}$

$\mathrm{J}=$ Moment of inertia

$\mathrm{f}=$ Coefficient of viscous friction

$\mathrm{T}_{\mathrm{g}}=$ Electromagnetic torque $(\mathrm{Nm})$

$\mathrm{P} \stackrel{\mathrm{g}}{=}$ Total pole pairs

$\lambda_{\mathrm{a}}=$ Amplitude of flux induced $(\mathrm{Wb})$

$\omega_{\mathrm{r}}=$ Angular velocity of rotor

$\mathrm{L}_{\mathrm{q}}=\mathrm{q}$ axis inductance $(\mathrm{H})$

$\mathrm{L}_{\mathrm{d}}^{\mathrm{q}}=\mathrm{d}$ axis inductance $(\mathrm{H})$

$\mathrm{R}=$ Resistance of stator winding (ohm)

$\mathrm{I}_{\mathrm{q}}=\mathrm{q}$ axis current $(\mathrm{A})$

$\mathrm{I}_{\mathrm{d}}^{\mathrm{q}}=\mathrm{d}$ axis current $(\mathrm{A})$

$\mathrm{V}_{\mathrm{d}}=\mathrm{d}$ axis voltage $(\mathrm{V})$

$\mathrm{V}_{\mathrm{q}}^{\mathrm{d}}=\mathrm{q}$ axis voltage $(\mathrm{V})$

$\mathrm{T}_{\mathrm{e}}^{\mathrm{q}}=$ Electro-magnetic torque $(\mathrm{Nm})$

$\mathrm{V}_{\mathrm{DC}}^{\mathrm{e}}=$ Boosted voltage $(\mathrm{V})$

$\mathrm{V}_{\mathrm{R}}=$ Rectified voltage $(\mathrm{V})$

$\mathrm{I}_{\mathrm{DC}}=$ Current across boost converter (A)

$\mathrm{I}_{\mathrm{R}}=$ Rectified current (A)

$\mathrm{T}_{\mathrm{ON}}=$ On-time of active switch ( $\mathrm{sec}$ )

$\mathrm{T}_{\text {OFF }}=$ Off-time of active switch (sec)

$\mathrm{T}=\mathrm{T}_{\mathrm{ON}}+\mathrm{T}_{\mathrm{OFF}}(\mathrm{sec})$

$\mathrm{T}_{\mathrm{ON}(\mathrm{PPT})}=$ PPT driving signal time ( $\left.\mathrm{sec}\right)$

$\mathrm{V}_{\mathrm{DC} \text { link }}=\mathrm{DC}$ link voltage $(\mathrm{V})$

$\mathrm{V}_{\text {ripple }}=$ Ripple voltage (V) 


\section{References}

1. International Energy agency. Technology Road Map, Wind energy 2013. Available at: <www.iea.org/publications/ freepublications/publication/Wind_2013_Roadmap.pdf>

2. Renewables 2014 Global Status Report. Available at: $<$ www.ren21.net/Portals/0/documents/Resources/REN21_ AnnualReport_2014_web.pdf $>$

3. Avoiding fossil fuel costs with wind energy. A report by the European Wind Energy Association 2014. Available at: $<$ www.ewea.org/fileadmin/files/library/publications/reports/ Avoiding_fossil_fuel_costs.pdf $>$

4. PIENKOWSKI C.A. The possibilities of using renewable sources of energy in podlaskie province. Pol. J. Environ. Stud. 19 (3), 537, 2010.

5. GUMULA S., PYTEL K., PIASKOWSKA-SILARSKA M. Environmental and economic benefits of using kinetic wind energy to generate electricity. Pol. J. Environ. Stud. 23 (6), 2014.

6. HERBERT G.J., INIYAN S., SREEVALSAN E., RAJAPANDIYAN S. A review of wind energy technologies. Renewable and Sustainable Energy Reviews. 11 (6), 1117, 2007.

7. ZINGER D.S., MULJADI E. Annualized wind energy improvement using variable speeds. IEEE Trans. Ind. Appl. 33 (6), 1444, 1997.

8. LI H., CHEN Z. Overview of different wind generator systems and their comparisons. IET Renew. Power Gener. 2 (2), 123, 2008.

9. CHAN T.F., LAI L.L. Permanent-magnet machines for distributed power generation: A review, in proceedings of IEEE Conference on Power Engineering Society general meeting, Tampa, 1, 2007.

10. CHINCHILLA M., ARNALTES S., BURGOS J.C. Control of permanent magnet generators applied to variable speed wind energy systems connected to the grid. IEEE Trans. Energy Convers. 21 (1), 130, 2006.

11. KAZMI S.M.R., GOTO H., GUO H.J., ICHINOKURA O. Review and critical analysis of the research papers published till date on maximum power point tracking in wind energy conversion system, in proceedings of IEEE conference Energy Conversion Congress and Exposition, Atlanta, 4075, 2010.

12. DALALA Z.M., ZAHID Z.U., YU W., CHO Y., LAI J.S. Design and analysis of an MPPT technique for small scale wind energy conversion systems. IEEE Trans. Energy Convers. 28 (3), 756, 2013.

13. AHMED R., NAAMANA., M'SIRDIN.K.,ABDELSALAM A.K., DESSOUKY Y.G. Sensorless MPPT technique for PMSG micro wind turbines based on state-flow, in proceedings of IEEE Conference on Renewable Energies for Developing Countries (REDEC), Beirut, 161, 2014.

14. KOUTROULIS E., KALAITZAKIS K. Design of a maximum power tracking systems for wind-energy- conversion applications. IEEE Trans. Ind. Electro. 53 (2), 486, 2006.

15. ABDULLAH M.A., YATIM A.H.M., TAN C.W. A Study of maximum power point tracking algorithms for wind energy system, in proceedings of IEEE Conference on Clean Energy and Technology, Johor Bahru, 321, 2011.

16. TAN K., ISLAM S. Optimum control strategies in energy conversion of PMSG wind turbine system without mechanical sensors. IEEE Trans. Energy Convers. 19 (2), 392, 2004.

17. HAQUE E., NEGNEVITSKY M., MUTTAQI K.M. A novel control strategy for a variable-speed wind turbine with a permanent magnet synchronous generator. IEEE Trans. Ind. Appl. 46 (1), 331, 2010.

18. UEHARA A., PRATAP A., GOYA T., SENJYU T., YONA A., URASAKI N., and FUNABASHI T. A coordinated control method to smooth wind power fluctuations of a PMSG-based WECS. IEEE Trans. Energy Convers. 26 (2), 550, 2011.

19. BHENDE C.N., MISHRA S., MALLA S.G. Permanent magnet synchronous generator-based standalone wind energy supply system. IEEE Trans. Sustain. Energy. 2 (4), 361, 2011.

20. LI S., HASKEW T.A., SWATLOSKI R.P., GATHINGS W. Optimal and direct-current vector control of direct-driven PMSG wind turbines. IEEE Trans. Power Electron. 27 (5), 2325, 2012.

21. KOTTI R., SHIREEN W. Maximum power point tracking of a variable speed PMSG wind power system with DC link reduction technique, in proceedings of IEEE Conference and Exposition PES General Meeting, National Harbor, MD, 1, 2014.

22. JESS. Wind turbine power calculations, published by Royal Academy of Engineering. Available at: <www.raeng.org.uk/ publications/other/23-wind-turbine>

23. MORIMOTO S., NAKAYAMA H., SANADA M., TAKEDA Y. Sensorless output maximization control for variablespeed wind generation system using IPMSG. IEEE Trans. Ind. Appl. 41 (1), 60, 2005.

24. GOUR R., JAIN P., MITTAL R., DESWAL S.S. PMSG based isolated wind energy conversion system (WECS) for variable load, in proceedings of IEEE Conference on Power Electronics (IICPE), Delhi, 1, 2012.

25. GUPTA R.A., SINGH B., JAIN B.B. Wind energy conversion using PMSG, in proceedings of IEEE Conference Recent Developments in control, Automation and Power Engineering (RDCAPE), Noida, 199, 2015.

26. BHARANIKUMAR R., YAZHINI A.C., KUMAR A.N. Novel maximum power point tracking controller for wind turbine driven permanent magnet generator, in proceedings of IEEE joint international conference on Power system Technology and Power India Conference (POWERCON), Delhi, 1, 2008. 
